\title{
La cuestión fantástica en el videojuego: entre la representación y la concepción propia
}

Fantasiazko gaia bideojokoan: irudikapenaren eta norberaren ikusmoldearen artean

The fantastic issue in video games: between representation and self-conception

\author{
Antonio Francisco Campos Méndez ${ }^{\star}$ \\ Universidad de Sevilla
}

RESUMEN: El objetivo de este artículo trata de desentrañar la construcción de la fantasía en el medio videolúdico, con una conciencia sobre su introducción en el germen cultural. Los primeros acercamientos al (video)juego han planteado una visión separada de la realidad, entendida desde una esfera propia y aislada. De tal forma, la presencia de la fantasía hace que el videojuego, a partir de sus propios mecanismos, elabore un entendimiento fantástico desde la amplitud de miras, tanto en influencias como en aportaciones propias.

PALABRAS CLAVE: videojuego; narrativa; cultura; medios de comunicación; juegos.

ABSTRACT: The aim of this article is to figure out the fantastic construction in the videoludic medium, with awareness of its introduction in the cultural seed. The first approaches to the (video)game have considered a separated vision of reality, understood from its own and isolated sphere. In that way, fantasy presence makes the videogame, from its own mechanisms, to develop a fantastic understanding with open-mindedness, both influences and its own contributions.

KEYWORDS: video game; narrative; culture; media; games.

\footnotetext{
* Correspondencia a / Corresponding author: Antonio Francisco Campos Méndez. Facultad de Comunicación de la Universidad de Sevilla, Calle Américo Vespucio, 27 41092-Sevilla) - antcammen@alum.us.es - https://orcid.org/0000-0003-4974-680X

Cómo citar / How to cite: Campos Méndez, Antonio Francisco (2021). "La cuestión fantástica en el videojuego: entre la representación y la concepción propia", Zer, 26(51), 163-180. (https://doi.org/10.1387/zer.22536).

Recibido: 11 febrero, 2021; aceptado: 25 junio, 2021.

ISSN 1137-1102 - eISSN 1989-631X / (c) 2021 UPV/EHU

(c) (i) $(ङ) \Theta$ Esta obra está bajo una Licencia

BY No No Creative Commons Atribución-NoComercial-SinDerivadas 4.0 Internacional
} 


\section{Introducción}

El videojuego, como parte intrínseca de la cultura masificada actual, ha prestado importante atención a la misma construcción idealista del ser humano. Es menester observar como la misma existencia del medio videolúdico queda supeditada a la acción del jugador, es decir, del ser humano, al realizar la actividad de jugar. Sin este hecho activo, el juego, sencillamente, no es, pues necesita de esa retroalimentación en el proceso comunicativo. En mayor o menor medida, el videojuego alude al jugador, haciéndole partícipe de la expresión y favoreciendo su inmersión para inmiscuirle en una esfera propia que le permita substraerse del exterior. Los elementos acaban siendo reconocibles a partir de la interacción y la repetición, de manera que no se requiere explícitamente de un primer vistazo para establecer una familiaridad.

Prestando atención al motivo que ocupa esta investigación, se presenta la cuestión de la construcción fantástica. La fantasía ha formado parte de la misma representación humana, entendida desde diversas perspectivas, que han permitido elaborar una imagen individual y colectiva de la cultura. De tal forma, distintas artes han establecido la fantasía como parte de su imaginario, introduciéndose como un género narrativo propio. Multitud de obras se entroncan dentro de esta consideración basándose en una serie de constructos populares a nivel social.

Siguiendo este hilo, cabe plantear la siguiente cuestión que concierne al artículo presentado: ¿cómo se desarrollan las grandes obras fantásticas en el videojuego? Considerando la base comunicativa del medio ludoficcional, su relación con el público es completamente diferente en gran medida. Aun con la influencia de diversos medios, el videojuego plantea en su interior una diferenciación considerable que se sustenta a partir de sus primeros acercamientos como pura actividad lúdica, sin consideración del componente narrativo, al menos, con suficiente desarrollo. En la actualidad, jugar posee numerosas implicaciones según lo planteado por lo que, tanto su desarrollo como su conclusión, pueden tener diversidad de significados. Sin embargo, a partir de las reglas es posible estructurar la experiencia jugable en cualquier ámbito considerado, permitiendo que el juego se haga evidente.

\section{Marco teórico}

\subsection{El VIDEOJUEGO COMO FORMA DE REPRESENTACIÓN Y SIMULACIÓN}

Antes de proceder a la cuestión del ámbito hipertextual, es conveniente observar la aplicación del juego como parte de la realidad. En tal forma, Huizinga plantea en Homo Ludens (1972), un acercamiento sobre la capacidad intrínseca del videojuego de absorber completamente al jugador del mundo corriente (1972: 33), creando de esta forma un "círculo mágico» que incluso posee consideraciones sacra- 
les. Es en este espacio elaborado donde funcionan las reglas propias del juego (1972: 42), sin poder aplicarse más allá del círculo. Esa esfera que crea el juego le da relevancia propia, apartada del mundo exterior y cotidiano, al recrear una nueva realidad propia.

De esta forma, tenemos un ámbito propio del juego que se configura a partir de unas reglas entendidas y respetadas (en principio) por sus participantes que, en relación a ello, se involucran en un entendimiento común sobre la esfera conformada alrededor de la actividad jugable.

Para Bateson (1954), muy en relación al postulado de Huizinga, el juego conforma un "caso de señales que están en lugar de otros sucesos», afirmando así una relevancia capital del juego en el avance del proceso comunicativo.» Cabe destacar la idea por parte de Huizinga sobre la concepción del juego previa a la cultura y que, incluso, acaba creándola desde un primer momento primitivo (1972: 13). Muy en consonancia con la idea del círculo mágico, aunque observada desde una alusión a la capacidad imaginativa del jugador, Bateson (1954) marca una necesidad consciente sobre la existencia en el juego.

En esa diferenciación de perspectivas que tienen como aspecto central la interpretación y aplicación por parte del receptor, Mendizábal (2004) realiza una simetría con los espejos y su capacidad reflexiva. De esta forma, se convierte en un «espacio semiósico», consistente es una "producción discursiva donde impera la realidad de un segundo espacio además de una realidad segunda dados por lo imaginario y lo simbólico» (2004: 48). En este aspecto, Mendizábal alude una cierta capacidad de realidad al juego, estableciéndose como un apartado propio. Sin embargo, cabe destacar esa mención de una "segunda realidad», con plena consciencia sobre el mundo inicial o «real» que, paradójicamente, acaba sirviendo como base para la conceptualización del videojuego, medio refundador gracias a «lo hipertextual y lo multimedial» (2004: 47). Es aquí donde el postulado de Huizinga comienza a encontrar problemas con la realidad.

No obstante, sigue habiendo reafirmaciones del círculo mágico y la capacidad creadora del (video)juego como un mundo alterno a la realidad. Jesper Juul (2008) diferenciaba tres perspectivas en el análisis del círculo mágico, supeditadas a la consideración realizada por el jugador en una determinada situación. De esta forma, el círculo mágico puede ser una, dos o todas esas perspectivas, según la experiencia extraída por el jugador. Para Juul (2008), estas consideraciones no se contraponen para negar el círculo mágico, sino que lo matizan y demuestran en qué consiste. Pero esta visión sigue dejando de lado aspectos intrínsecos de la misma definición del círculo mágico. Para Huizinga (1972), la verdadera importancia del juego residía en ese círculo mágico, alejado de cualquier forma del exterior y sin afección alguna. Esta última apreciación entraña una dificultad de afirmación, en tanto que el videojuego 
requiere de tiempo real en su empleo que, en consecuencia, afecta a la perspectiva vital de los participantes (Egenfeldt-Nielsen, Heide Smith, Tosca, 2015: 34-35).

Entrando a considerar el propio desempeño del videojuego con la realidad, encontramos acercamientos muy interesantes. Para Collantes (2013), existen dos tipos de juegos según su realidad: juegos que aluden a la realidad en sí misma, denominados juegos compactación y juegos que representan una realidad, nombrados como juegos representación (2013: 25). Los primeros permiten observar una nueva realidad, elaborando una perspectiva narrativa propia que empieza y acaba en el mismo ámbito de juego (2013: 27). Por su parte, los juegos representación se estructuran en una doble vertiente, consistente en las reglas sobre aquella realidad que representa y las mismas reglas del componente lúdico (2013: 29).

No obstante, Collantes también otorga una importancia crucial a la observación de la (no) realidad del videojuego según la visión de un autor que incluso predispone las opciones de las que goza el jugador (2013: 34). De entre todas estas opciones, se establece la conclusión obtenida de la experiencia. Para Huizinga, la verdadera relevancia de lo ocurrido queda dentro de la esfera y para aquellos que han sido partícipes en ese mismo espacio (1972: 86), aunque la verdadera recompensa se encuentre fuera, en el mundo cotidiano. En palabras del mismo Huizinga, «no se juega por ella, pero si se trabaja por ella» (1972: 88). Sin embargo, en esta misma definición, se encuentra una contradicción al entender que la realidad efectivamente sí posee consideración en la esfera jugable, al ser contenedora de la recompensa y/o experiencia obtenida.

Collantes (2013) opta por dar preferencia a la misma actividad de juego por encima de la conclusión en sí:

La perspectiva lúdica supone la comprensión del acontecimiento a partir de un esquema narrativo según el cual dicha actividad está encapsulada. Se trata de una perspectiva en la que las consecuencias del resultado del juego se dejan en suspenso, pues lo importante es el propio desarrollo del juego, las jugadas que se hacen, la pericia y habilidad de los jugadores, las alternativas en la marcha del resultado e incluso el propio resultado final, pero lo que ocurre a partir de ese punto ya no forma parte del juego ni de la narración que define. (2013: 41)

\subsection{La FAnTASía: Mitología, MUNDOS y JUEgo}

Con este planteamiento sobre la idea de juego, es momento de regresar a la cuestión de la fantasía. Uno de los primeros acercamientos, esencial en la posterior expansión de los estudios sobre la fantasía, es el postulado sobre la creación de lo 
fantástico establecida por Todorov (1982). Para el lingüista, existen distintos fenómenos que marcan la idea fantástica en un relato según los hechos presentados. Por un lado, se encuentra la presencia de lo misterioso, sustentado sobre acontecimientos que limitan con lo asumible, pero explicable dentro del ámbito terrenal. En el otro extremo se encuentra la presencia de lo sobrenatural, aquello que claramente supera los límites de lo explicable según los criterios terrenales. Justo en medio de esas dos concepciones se encontraría lo fantástico, pero no como algo evidente, sino como una disyuntiva constante. Todorov (1982) establece que la resolución de esta diatriba puede llegar a quebrar lo fantástico, hacerlo algo reconocible, aunque no pueda ser explicable, por lo que el mantenimiento de esa disyuntiva hasta su conclusión e incluso posteriormente, es un aspecto clave (1982: 14-15).

Muñoz (2010) se acerca a la teorización de Todorov, pero siendo mucho más resolutivo en la apreciación narrativa sobre el hecho percibido como sobrenatural que "cuestiona las leyes del funcionamiento del mundo" (2010: 6-7). Como si de una ampliación extensa se tratase, Roas (2009) trata la imposibilidad del fenómeno, supeditada a aquello que es inexplicable según "la concepción que tenemos de lo real» (2009: 94). Tanto es así que incluso lo considera esencial para la creación fantástica, siempre y cuando quede circunscrito como parte del mundo real, de tal forma que lo fantástico acabe introduciéndose de forma alterada. Sin embargo, en lo que respecta a la contemplación de la realidad, Castro (2016) no sólo ciñe la elaboración fantástica a una inversión de lo real, sino también al «alterar las bases de la realidad» (2016: 4).

A este respecto, cabe destacar la influencia de la mitología en la creación fantástica. Para Bettleheim (1976), no existe una «división clara que separe el mito del cuento popular o de hadas», sirviendo como principio para las «sociedades preliterarias» (1976: 29). Siguiendo en este proceso, Castro (2016) sí realiza una categorización en forma de "fundamento primigenio de la fantasía épica» (2016: 19). De aquí surgen las ideas sobre dioses, héroes y mundos de nueva creación alejados del nuestro. Se plantean ciertas características asociadas a la fantasía, tanto en su estructuración como en el avance y evolución conocido. Al poseer una mirada consciente hacia lo real, Castro (2016) establece una marca identificativa del mundo medieval en la fantasía épica. Por extensión, existen diversos espacios que se emplean constantemente en obras fantásticas, tales como los castillos o los bosques (2016: 7). Un paso más allá estaría el Secondary Belief, muy en sintonía con el círculo mágico de Huizinga, consistente en un "hechizo temporal» que envuelve al receptor en el texto en cuestión (Castro, 2016: 8). Este hechizo se rompe en el momento que en ese Secondary Belief, la suspensión de la incredulidad se ve trastocada (Nikolajeva, 2003: 153-154).

Para potenciar la elaboración fantástica y, por extensión, su carácter envolvente sobre el receptor, escritores como Lovecraft o Tolkien, establecieron las bases del mythmaking, la creación de un mundo nuevo, con una mitología propia y ale- 
jada de la conocida en nuestro mundo (Castro, 2016: 10). Donaldson (1986) denotaba la efectividad de este modelo (extendido hasta nuestros días) gracias a la propia capacidad del ser humano de identificarse con ideas heroicas de amplias proporciones, pero en un ambiente sin "conexión con la realidad de quiénes somos y que hacemos» (1986: 17). La creación de mundos alternos basados en nueva mitología sigue muy de cerca la teoría de mundos posibles que se establece a partir del «universo del discurso", superando las barreras del mundo real y sus estructuras (Dolezel, 1998: 40).

En relación a su aplicación en el juego, la fantasía permite el desarrollo directo por parte del receptor, creando «una retórica única y una variedad transformadora» (Rick, 2019: 122). Es por ello crucial entender la postura del receptor, en este caso, jugador, al asumir la "existencia» de tales personas como reales dentro del «campo de la simulación» (Dolezel, 1998: 27). Para Bowman (2010), el jugador se desempeña en este mundo alterno de juego a partir de la creación de un personaje como «el crecimiento de una semilla» (2010: 156). Desde aquí, el jugador trata de buscar que ese crecimiento le permita desarrollarse de forma libre a través de aquello que quiere expresar. Esta visión, aunque pertinente en cuanto a la crucial figura que desempeña el jugador, se ciñe exclusivamente en la idea de los role playing games (RPG) y, más concretamente, en aquellos de mesa regidos por la figura de un master. Al llevar este planteamiento a los videojuegos, incluso en los RPG existe una aplicación diferenciada, pues el jugador no siempre posee la libertad para crear un personaje inicial a su gusto. De tal forma, el tratamiento fantástico cuenta con una amplitud de caminos a partir de la categorización de género, una cuestión de dificil resolución.

\subsection{LA PROBLEMÁtiCA SOBRE LA CLASIFICACIÓN POR GÉNEROS}

La consideración tipológica del videojuego ha persistido en un constante debate sobre los criterios a seguir. En el terreno más popular, concerniente al aspecto comercial, la diferenciación es más simple, sobre todo para hacer más ameno el acercamiento por parte del público. Sin embargo, al entrar en la cuestión investigadora, distintas perspectivas acaban mezclándose para aportar una visión dispersa sobre la condición del medio. Todo ello sin considerar el apartado puramente argumental, concerniente a la temática y narrativa dispuesta. Precisamente, este componente ha tratado de circunscribirse a aspectos intrínsecos del medio, de tal forma que sirva como un ente colaborativo más.

En este artículo, se han tratado de establecer dos acercamientos a la cuestión que, posteriormente, permitan una mayor eficacia en el análisis fantástico del videojuego. El primero de ellos fue realizado por Oliver Pérez Latorre desde diversos ámbitos y consideraciones del medio. Latorre (2011) establece cuatro criterios 
para determinar el género de los videojuegos, retroalimentándose entre ellos. Desde la dialéctica asimilación/acomodación (a partir de la psicología del aprendizaje), siguiendo la estructura de juego y la finalidad del jugador implícito, hasta llegar a la dominante de las mecánicas de juego (2011: 131).

En la primera consideración, aplicando los postulados de Piaget, Latorre (2011) distingue entre juegos simbólicos, alusivos a la pura imaginación, juegos de acomodación, en los que se busca la adaptación a un entorno externo, pero conocido, y juegos de competición, a medio camino entra las dos tipologías anteriormente mencionadas (2011: 133). Asimismo, el investigador sitúa los videojuegos como parte de los juegos competición, aunque le añade componentes asumibles con el resto de categorías. Siguiendo con las estructuras de juego, tomando como base la dualidad paidea-ludus de Caillois, realiza una distinción pertinente entre las reglas de juego y el gameplay aplicado. De tal forma, es posible hablar de sistema paidea, donde las reglas son mucho más flexibles, y sistema ludus, en el cual las reglas de juegos están más formalizadas. A partir de aquí, se empieza a considerar la perspectiva jugable, según si se presentan bucles constantes de dinámicas o el (video)juego en cuestión admite diversas estrategias (2011: 135). En el siguiente apartado, el foco se centra en aquello que el videojuego requiere del jugador, en relación con el gameplay que desarrolla. Aquí, la clasificación se hace mucho más reconocible con el entorno popular del medio, distinguiendo entre videojuegos de acción (victoria/derrota con un gameplay rígido), videojuegos de estrategia (victoria/derrota con un gameplay abierto), videojuegos de aventura (descubrimiento narrativo con un gameplay rígido), videojuegos de rol (descubrimiento narrativo con un gameplay abierto), videojuegos como simulador (comprensión del sistema con un gameplay rígido) y videojuegos de simulación (comprensión del sistema con un gameplay abierto). Esta categorización posee una estrecha relación con la consideración en el género de los videojuegos realizada por Egenfeldt-Nielsen, Heide Smith y Tosca (2015), de la que hablaremos más adelante. Por último, en conjunción con lo anteriormente expuesto, Latorre se acerca a la cuestión dominante en las mecánicas de juego. Para ello, utiliza componentes asimilados con el comportamiento primitivo y la asociación competitiva (agon), así como sus matizaciones. De tal forma, quedan estipulaciones asociadas con la recolección, la captura, la configuración o construcción y la carrera. Estas cuatro cuestiones supondrían las mecánicas predilectas en los (video)juegos y, aunque es posible clasificar distintos títulos en cada una, la riqueza del medio acaba provocando retroalimentación entre todas ellas (2011: 142).

Es aquí donde la categorización de Latorre acaba encontrando límites, al ser consciente de la existencia de títulos cuya clasificación acaba presentando matices de dificil aclaración. Títulos de gran amplitud como Grand Theft Auto V (Rockstar, 2013) o Metal Gear Solid 2 (Konami, 2001) acaban provocando una problemática en la categorización por géneros, pero también asumen ese avance constante que supone el medio videolúdico (Latorre, 2011: 143). 
En estas alteraciones se podría incluir la condición fantástica, en tanto que acaba introduciéndose en multitud de títulos de distinta consideración sin un paradigma claro. Bien es cierto que la fantasía posee una relevante cercanía al RPG, por lo que presentaría un gameplay abierto en el descubrimiento narrativo, incluso otorgando autonomía en el origen y desarrollo del avatar/jugador. Sin embargo, es posible circunscribir la fantasía en otra serie de títulos de difícil consideración, e incluso dentro del RPG, sus tratamientos son dispares, poniendo incluso en cuestión la condición libre del avatar del jugador.

Precisamente, centrando la clasificación de géneros en la figura del jugador, Egenfeldt-Nielsen et al. (2015) proponen un modelo basado en los requerimientos en el jugador para poder alcanzar el objetivo propuesto por la obra en cuestión. En primer lugar, se encontrarían los videojuegos de acción, necesitando de habilidades motoras que permitan la coordinación entre la visión y la respuesta táctil. Los videojuegos de aventuras, por su parte, requieren de paciencia y reflexión para poder desentrañar los desafíos propuestos, comúnmente representados en forma de puzles. La siguiente tipología se centra en los videojuegos de estrategia, subdivididos en estrategia en tiempo real que necesitan de acciones rápidas por parte del jugador y la estrategia por turnos, con decisiones pausadas. Por último, existen también videojuegos de procesos orientados, sin un objetivo claro y que buscan la completa inmersión por parte del jugador (2015: 56-57).

Esta clasificación, aunque interesante y contemplando con atención la figura del jugador en la experiencia completa, sigue siendo excesivamente rígida. La intención de circunscribir los videojuegos a categorías concisas acaba por presentarse como nula, al menos en su función completa. Su utilidad demuestra los puntos de unión que existen entre distintas tipologías y, una vez más, la notable riqueza del medio. No obstante, tanto el apartado sobre la distinción rigidez/apertura en el gameplay de Latorre como la funciones y actitudes del jugador en la experiencia, serán elementos muy considerables en el análisis sobre la fantasía videolúdica.

\section{Metodología de análisis}

Una vez planteadas cuestiones pertinentes al videojuego, ya sean derivadas o intrínsecas del mismo, es el momento de establecer los distintos aspectos concernientes a la construcción fantástica en el medio videolúdico que serán parte del análisis. Dada la amplitud del tema planteado, la metodología empleada para este análisis trata de exponer por separado tanto la propia condición fantástica, como la estructuración lúdica para, posteriormente, reunir ambas concepciones en un último apartado de análisis. Para ello, se recurre en primera instancia a la construcción del mundo, atendiendo a su misma concepción para con la experiencia, así como a las disposiciones establecidas en el medio según su referencialidad y/o adaptación masificada, 
prestando especial atención a la relación que se establece con el jugador durante el proceso. Se seguirán varios de los postulados, obras y/o escenarios comunes planteados en el marco teórico, realizando una asimilación sobre su origen, así como su tratamiento en el mundo de juego. El siguiente paso será concretar las reglas de juego, un apartado en el que tomará relevancia el asunto sobre el género jugable, presentando cercanías y distancias con los postulados planteados por Pérez Latorre sobre este asunto. En este análisis, se han tratado de reunir diversas sensibilidades, principalmente al considerar las mecánicas y la actitud del jugador al ponerlas en prácticas según las dinámicas de juego. Este elemento adquiere suma relevancia al disponer las reglas de juego predilectas según los estándares entendidos para cada clasificación. Al presentar tantísima riqueza dentro de los mismos géneros predilectos, es importante señalar sus particularidades y las disposiciones que se establecen para el desarrollo del jugador en la experiencia. Por último, este análisis se extiende a la narrativa dispuesta y la expresión derivada, donde cobra especial importancia el alcance histórico del medio y su variable representación. En este apartado, la construcción fantástica y su desarrollo en términos videolúdicos cobran absoluto protagonismo, erigiéndose como núcleo de conjunción entre ambas disciplinas, siguiendo parte de la corriente narratológica en los game studies. Del mismo, se establece una intencionalidad cuasi evolutiva en lo que respecta a su afección en distintos parámetros del medio y, en particular, de la construcción fantástica a partir de los dos elementos de análisis anteriormente mencionados.

\section{Análisis}

\subsection{Construcción de Mundo}

Prestando atención a la consideración cultural, es conveniente partir desde el componente mitológico en la construcción fantástica. Esta elaboración es sumamente relevante en el circuito más popular del medio. Por ejemplo, las dos últimas entregas de la saga Assassin's Creed, Origins (2017) y Odyssey (2018), se ambientan en una adaptación de Egipto y Grecia respectivamente (Venegas Ramos, 2018). Recientemente, como parte de esta nueva recreación mediada, la última entrega de la saga, Valhalla (2020), sitúa al jugador en la cultura nórdica. Estas obras se circunscriben al manejo de un personaje que va escalando en el naciente credo de los Asesinos para atacar aquellas esferas de poder que tratan de imponer su dominio sobre el mundo a partir del uso de un artefacto conocido como Fruto del Edén. Tanto en Origins como en Odyssey se acaba aludiendo directamente a seres y/o hechos propios de la mitología de cada región. En el primero se recrean combates contra distintos dioses egipcios, conocidos como Pruebas de los Dioses, algo que en el segundo se amplió al enfrentamiento contra criaturas clásicas de la mitología griega, tales como el Minotauro o la Gorgona. 
Esto se extiende a la misma figura del personaje con respecto al mundo a su alrededor. En Origins, Bayek es el asesino protagonista que va en busca de aquellos que acabaron con su hijo. Cuando finalmente acaba encontrando y asesinando a cada uno de estos enemigos principales, se reproduce una cinemática en la que, una vez muerto, el enemigo en cuestión tiene una conversación con Bayek. Este momento se da en una especie de limbo etéreo, como si de un paso previo a la muerte espiritual se tratase, donde Bayek utiliza una pluma para acabar definitivamente con su enemigo. Esta secuencia ya existía en el resto de la saga, pero en este título se amplía a una visión basada en la creencia vital y ceremonial egipcia. Por otro lado, en Odyssey, el personaje controlado por el jugador, ya sea Alexios o Kassandra, al enfrentarse con el resto de enemigos, desempeña una habilidad que incluso se acaba equiparándose a una dinastía proveniente de los dioses griegos. Son varios los ataques en forma de explosiones que afectan a un área amplia, todos ellos provocados por la fuerza sobrehumana de su cuerpo. En cierto modo, al estar anclada a una representación reconocible del mundo, acaba derivando hacia una inspiración fantástica basada en la influencia sacramental y una persistencia mitológica reelaborada en su propio universo.

Tal y como se ha comentado anteriormente, existen obras que sirven como modelo esencial para la creación de mundo en diversas disciplinas. El Señor de los Anillos (J.R.R Tolkien, 1954) fue un momento cumbre para muchos autores/as que elaboraron el mapa de sus obras a partir del modelo de la Tierra Media. Siguiendo este planteamiento, el videojuego ha elaborado muchos de sus territorios a partir de este mapeado. Sagas como The Elder Scrolls (Bethesda Softworks, 1994), Baldur's Gate (Bioware, 1998), o Dragon Age (Bioware, 2009), apuestan por una creación de mundo tolkieniana, basada en la misma disposición y reconocimiento de criaturas fantásticas, elaborando disputas en las que incluso el jugador pueda ser partícipe y añadiendo elementos a su recorrido heroico. No existe, por tanto, una mirada consciente al folklore y/o mitología que ha recorrido la cultura social, sino una retroalimentación de factores argumentales del género fantástico. No obstante, hay casos de gran popularidad que rehúyen esta construcción, como The Witcher 3: Wild Hunt (CD Projekt, 2015), un videojuego que, a primera vista, parece recrear un mapa y mundo claramente basados en la obra de Tolkien, pero cuyas criaturas acaban derivando la perspectiva sobre su propio espacio, aludiendo a un folklore europeo muy presente en los cuentos populares.

En esta primera aproximación, se ha tratado la visión occidental en cuanto a la elaboración fantástica. Sin embargo, al dirigir la mirada al terreno oriental, las perspectivas cambian sobremanera en lo que a la construcción de mundo respecta. Siguiendo el planteamiento tolkieniano, la derivación más clara en la industria japonesa del videojuego es Dark Souls (From Sofware, 2011). La saga de From Software, representada hasta el momento por tres títulos más el primer Demon's Souls (2009) (así como su remake, realizado por Bluepoint en 2020), cuenta con una ambien- 
tación aparentemente muy cercana a la dispuesta por el autor británico, sobre todo en lo que al mapeado se refiere. Pero al considerar los distintos seres que habitan el mundo, tanto en forma de enemigos como de secundarios, la perspectiva cambia considerablemente. Dark Souls posee una inspiración mitológica planteada desde la primera cinemática, con el germen cosmogónico en el enfrentamiento entre poderosos seres y los inmortales dragones. A este respecto, se establece una alusión directa a la mitología griega, con representaciones a deidades tales como Zeus y criaturas clásicas como el Minotauro. Asimismo, la presencia de seres fantásticos tradicionales, como los dragones, también son muy recurrentes. Sin embargo, el tratamiento otorgado por la saga es muy interesante, concerniente sobre todo a la consideración temática. Al introducir todas estas inspiraciones eminentemente europeas en una mentalidad oriental, la representación anteriormente comentada del germen mitológico entra en el terreno de la decadencia. Gwyn, el personaje inspirado en la figura de Zeus, es denominado con el sobrenombre de Señor de la Ceniza, un dios venido a menos por la avaricia y el poder. Del mismo modo, el Minotauro clásico se ve reducido a la aparición de un enemigo final denominado Demonio de Tauro que acaba siendo derrotado en las primeras instancias del juego. Incluso los dragones, criaturas representadas como magnánimos en otros universos, aquí se ven reducidos a la aparición de sus cadáveres y esqueletos.

Esto se extiende incluso a la representación de los espacios. Muchas de las zonas en estos mundos retrotraen a un imaginario fantástico clásico, con enormes castillos donde habitan grandes reyes, bosques inmensos que la vista no alcanza a discernir e importantes fortalezas para defender de los asedios. Todos estos espacios forman parte del mundo de juego, pero su significación es inversa. El único gran castillo que se puede encontrar en el primer Dark Souls es Anor Londo, donde precisamente habitaba Gwyn, pero en el momento de llegada del jugador no queda nadie y, de hecho, el sol que alumbra esta zona (en contraposición a la persistente oscuridad del resto del mundo) es, en realidad, una farsa.

Siguiendo con From Software, lo cierto es que la empresa japonesa ha realizado otras dos obras muy en consonancia con la saga Souls como son Bloodborne (2015) y Sekiro: Shadows Die Twice (2019). Estos videojuegos, caracterizados principalmente por su dificultad, poseen entendimientos sobre la fantasía muy diferenciados. En el primero, la ambientación victoriana se une a una inspiración lovecraftiana consistente en la cercanía del ser humano a grandes seres de poder, contenedores de conocimiento y saber sobre su propio universo. Para ello, Bloodborne se sirve de una reflexión sobre el paso entre mundos y la influencia que se ejerce en cada acción. Por su parte, Sekiro se sitúa en una representación del periodo Sengoku en el Japón feudal, al que se añaden elementos fantásticos que se asumen como naturales en el universo planteado. Sekiro reúne en su mundo jugable transiciones hacia espacios etéreos ligados a una creencia trascendental, así como la transposición de tiempos a partir del mismo avatar manejado, como por la presencia de diversos personajes. 
No obstante, cabe comentar que estas obras son más bien una particularidad dentro de las propuestas principales que aparecen desde Oriente. Siguiendo en Japón, uno de los grandes países en lo que a producción de videojuegos se refiere, Square Enix se ha erigido como una gran compañía realizando importantes sagas representativas tanto de la fantasía en el videojuego como del género RPG. Son varias las sagas que se podrían mencionar, pero entre ellas destacan tres que, aun a día de hoy, siguen teniendo un importante calado en el medio como son Dragon Quest (1986), Final Fantasy (1987), y Kingdom Hearts (2002). En la primera saga mencionada, la propuesta se centra en una visión medieval de caballeros y grandes castillos, donde la fantasía se introduce de forma natural, al reconocerse criaturas muy particulares como parte de un bestiario propio en este mundo. El aspecto del mundo, así como de los seres que lo habitan, lejos de ser intimidante, trata de aportar una cierta relajación cómica. Final Fantasy ha seguido una paulatina evolución en la construcción de su mundo, desde una mirada a los cuentos tradicionales basados en una representación medieval fundida con componentes mágicos, hacia la incorporación de la industrialización. En cierto modo, trata de configurar un mundo reconocible en el que los componentes fantásticos puedan introducirse más como parte de la ciencia y tecnología de ese universo. Existen elementos tradicionales dentro de la saga, como los cristales de poder que son objeto de deseo durante el relato y criaturas que forman parte de una cierta identidad, como las invocaciones abismales o los chocobos (criaturas propias del universo Final Fantasy, incluso como marca referencial). Finalmente, Kingdom Hearts bien podría considerarse una mezcla de las sensibilidades de las dos sagas anteriormente mencionadas. Su universo es sumamente particular, apoyado sobre las bases de una aventura desenfadada, se estructura a partir del recorrido de distintos mundos que recrean películas Disney, pudiendo interaccionar con sus personajes. Estos hechos están supeditados a la referencia cinematográfica dentro de un conglomerado argumental bastante complejo.

\subsection{Reglas De JUego}

En primer lugar, cabría hablar de la relación de la interacción que se establece con el mundo de juego. Aunque, tal y como se ha comentado, la fantasía en el videojuego establece mundos alternos en los que diversas criaturas y acontecimientos se estructuran como propios y naturales, lo cierto es que buena parte de su participación con el jugador se estructura a partir del enfrentamiento. Sin embargo, el tono dispuesto puede manifestar unos planteamientos $\mathrm{u}$ otros. Tomando como ejemplo la saga Dragon Quest, su colorida presentación establece un acercamiento sencillo y ameno por parte del jugador, incluso en los combates contra los diversos enemigos. Aun con la naturalidad que dispone el videojuego fantástico, la actitud suele ser conflictiva, como si formara parte fundamental del entendimiento aventurero. No obstante, con el avance del medio, se han ido introduciendo nuevas perspectivas para poder evitar la batalla. Obras como Dragon Age: Origins (Bioware, 2009), The Elder 
Scrolls V: Skyrim (Bethesda, 2011) o el mencionado anteriormente The Witcher 3 incluyen el enfrentamiento como parte de sus dinámicas, pero también permiten el desarrollo más pacífico por parte del jugador a partir de habilidades sustentadas en el diálogo.

Se ha hecho mención de forma implícita a un género jugable esencial en el entendimiento fantástico como es el RPG. La relación del jugador con el mundo dispuesto depende en gran medida de las reglas que adopte el videojuego, algo que se sustenta en la categoría que se circunscriba. Es posible delimitar esta consideración a las reglas de juego, pero incluso ahí habría una diversificación importante. El RPG más tradicional (y más ligado a la perspectiva oriental) basa sus enfrentamientos en un combate por turnos. El componente estratégico juega un papel esencial a este respecto, con un jugador que maneja a un grupo conformado (normalmente) a su elección y estilo. En este escenario, su relación se basa en un entendimiento sobre las necesidades de cada nuevo enfrentamiento, considerando las debilidades y fortalezas de cada situación. Es algo muy extendido en la saga Pokémon (Game Freak, 1999), cuya distinta tipología de criaturas invita a diversas interacciones, requiriendo de un entendimiento dual entre dinámicas y mundo dispuesto.

Al igual que ocurre en Pokémon, la saga Final Fantasy comenzó estableciendo combates aleatorios. La dinámica en estas obras consistía en que, en cualquier momento de su recorrido, el jugador podía encontrarse con una situación de combate sin previo aviso. Más allá de los enfrentamientos contra enemigos finales, estas luchas solo son posibles de prever al recorrer zonas reconocibles, como hierbas altas en la saga Pokémon. No obstante, esta disposición ha ido variando hasta un reconocimiento actual de las criaturas a enfrentar, de tal forma que es posible evitar los combates. Con ello, el acercamiento por parte del jugador varía considerablemente, al poder elegir los momentos y situaciones en las que proceder al conflicto. Sin embargo, el RPG establece otra serie de dinámicas que afectan a esta cuestión. El escalado por niveles presenta una experiencia que requiere del desarrollo del avatar por parte del jugador a partir de la mejora de diversas habilidades. Para poder obtener estas mejoras, ya sea de forma directa o indirecta, el jugador debe entrar en combate, vencer y obtener puntos de habilidad o experiencia. Según el sistema de desarrollo, el jugador podrá elegir donde emplear estos puntos o, en contraposición, estos se dispondrán automáticamente por el juego. Paradójicamente, este sistema permite el avance del jugador a partir de retos finales que requieren de cierto nivel y que, normalmente, se presentan como enfrentamientos más complejos.

Esta elaboración permea sobre el RPG en general, sea un acercamiento u otro. Si hablamos de un Final Fantasy o un Dragon Quest, los cambios en las subidas de nivel se sustentarán en habilidades añadidas a las opciones estratégicas de combate, a mayor vitalidad o a una potencia considerable en el ataque. Por otro lado, si tratamos algún videojuego de la saga Souls, las habilidades de combate (confeccionadas 
por el jugador) permitirán acudir a los enfrentamientos finales con un mayor poder, pero también se requerirá de una experiencia y un entendimiento del enemigo en cuestión. A este respecto, el acercamiento del jugador entre una propuesta jugable $u$ otra difiere según las mecánicas y dinámicas concernientes al combate en cuestión.

Tal y como se ha comentado anteriormente, es posible evitar los enfrentamientos (no siempre) recurriendo a opciones de diálogo. En estas situaciones, el jugador también requiere de un desarrollo del personaje, aunque de otra índole. La actitud por parte del jugador se establece como conciliadora, entendiendo el mundo y su avatar como un conjunto de pervivencia que se entiende como partes necesarias. Igualmente, su presentación es muy diversa. En Skyrim, las mismas opciones de diálogo permiten al jugador entablar unas relaciones u otras con los distintos PNJ. La resolución en favor del jugador en las situaciones de diálogo se subraya con una actitud, ya sea conciliadora o violenta, y su capacidad de consecución, supeditada a la habilidad que posea el avatar en este apartado. Para aumentar esta probabilidad, se requiere de la repetición y el éxito continuado en este tipo de situaciones. Por tanto, es un ciclo que el jugador adopta en contraposición a otra serie de opciones, dirimiendo en una cierta actitud para con la experiencia. Precisamente, esta actitud es posible extenderla a otras obras cuyas opciones de diálogo son más limitadas, pero de un recorrido igual o incluso más sustancial.

\subsection{NARRATIVA y EXPRESIÓN}

La persistencia en la distinción entre el aparato jugable y la narrativa de la obra ha conllevado un planteamiento disperso. Es cierto que las formas de entendimiento entre ambas perspectivas provocan desequilibrios en la expresión final. No obstante, incluso estas disonancias establecen una discusión pertinente sobre la relevancia en el acercamiento al medio. La fantasía, al ser un género recurrente desde los mismos inicios del videojuego, ha conocido diversidad de formas en el relato. Principalmente, se encuentra muy en relación al género jugable dispuesto, siguiendo una serie de convenciones entendidas y promovidas incluso por los jugadores. No obstante, sus primeras estructuraciones eran simples, con alusiones a mundos alejados y atrasados tecnológicamente.

Con la introducción de nuevos iconos, tales como Super Mario (Nintendo, 1985), Link de The Legend of Zelda (Nintendo, 1986) o los personajes (en sus inicios desconocidos) de las primeras entregas de Final Fantasy, el medio fue conociendo nuevos tratamientos sobre los distintos mundos jugables, pero la narrativa seguía anclada en una adición sin sustancia. En la década de los 90, distintos géneros narrativos consiguieron hacerse un lugar entre formas de juego reconocible. La narrativa de estas obras buscaba una doble función complementaria: introducir al jugador en su mundo a partir del reconocimiento no sólo externo (el mundo real) sino también, interno. 
En cierto modo, la fantasía más clásica siguió este rumbo, pero tornando hacia nuevas formas de concebir su universo. Final Fantasy VII (Squaresoft, 1997) marcó un antes y un después en la forma de concebir los RPG por turnos en todo el mundo. Desde la industrialización, el mundo fantástico fue circunscrito al apartado científico de relato que aludía a problemáticas sociales reconocibles por parte del jugador. De tal forma, la familiaridad del jugador con la experiencia no sólo se basa en el mundo establecido, sino también en una narrativa de velada denuncia y, sobretodo, con un componente emocional muy potente.

La estructura de su guion alude directamente al viaje del héroe, con importantes detenimientos en la condición del grupo. El jugador maneja a varios personajes en las batallas, pero el relato se centra en Cloud, su relación con el mundo, con sus amigos y con Sephiroth, el oponente del relato. La narrativa presenta una serie de alteraciones en la fórmula clásica que provienen de la propia condición del videojuego, con una presentación alternativa entre cinemáticas y transiciones sin el control del jugador. En su lanzamiento original, dividido en tres discos, el equipo creativo se sirvió de cliffhangers sumamente potentes que daban aun mayor eficacia a la expresión. Con todos estos elementos, Final Fantasy VII consiguió convertirse en un éxito de masas al presentar una historia reconocible y amena, con un fondo temático centrado en unas sensaciones reconocibles por parte de los jugadores que permitiera una unión mucho más cercana con el avatar, aun cuando existía una cierta distancia jugable. La saga seguiría con esta corriente creativa en las obras venideras, presentando relatos a medio camino entre una fantasía autorreferencial y una construcción de mundo reconocida por el jugador.

La narrativa, por tanto, acaba introduciéndose de lleno en la construcción de mundo y planteando debates sobre la condición fantástica en el videojuego. Al aludir directamente a componentes como la representación distópica del mundo corriente, la esfera propia del juego se resquebraja. No obstante, el avance histórico también regresa a la concepción más tradicional. La inmensidad en los mundos de juego, al igual que las posibilidades de interacción, hace que decisiones del jugador marquen el relato emergente. Para centrar la acción, estas obras introducen un objetivo principal, pero sin consideración de tiempo o necesidad por delante de la misma intención del jugador. No obstante, el rumbo elegido puede llegar a interferir en las conclusiones, no sólo por las distintas ramas de finales, un elemento muy presente en numerosos videojuegos, sino por el desarrollo de las mismas.

Es una corriente compartida por la saga Souls, pero con un desempeño diferente. Su narrativa es sumamente peculiar, con reminiscencia de los primeros The Legend of Zelda. Tanto es así que acaba siendo un recorrido histórico sobre su propio universo, fundiendo las ideas clásicas sobre tiempo y espacio. De tal forma, la esfera jugable se hace completa al circunscribir el relato al mundo planteado, con una funcionalidad y expresión propias. De aquí surge la idea de las derrotas narrati- 
vas (Campos Méndez, 2019: 34), elementos propios de la configuración expresiva de estas obras que entronca en la comprensión sobre el universo jugable. Las derrotas narrativas se establecen en mundos abiertos donde el jugador puede marcar su propio camino, por lo que también es aplicable a sagas anteriormente mencionadas como The Elder Scrolls, Fable o incluso Final Fantasy. No obstante, estos planteamientos se centran sobre todo en el desarrollo del jugador dentro de la experiencia, mientras que en la saga Souls estas derrotas narrativas afectan a la comprensión propia del mundo.

\section{Conclusiones}

El juego y el videojuego miran al mundo cotidiano, no sólo en términos de representación, sino en la elaboración más intrínseca de su existencia. Muchos de los fenómenos reconocibles se sirven efectivamente de una herencia lúdica que incluso entraña a la misma consideración cultural, pero su aplicación no es aislada y, de hecho, no busca serlo. Su relación con el ser humano ha sido cambiante y expansiva, en tanto ha conocido nuevas formas de expresión y amplificación, sin estar ceñida a un condicionamiento de retroalimentación en su proceso comunicativo. No obstante, aun negando la existencia de concepciones del videojuego tales como su aislamiento total del mundo cotidiano, es pertinente reconocer la capacidad del medio para adoptar discursos reconocibles y deformarlos. La recurrencia mitológica de obras como Dark Souls aluden a una evidencia mundana pero también a un interés por reelaborar la consideración clásica a partir de su reunión con otras sensibilidades alejadas de su creación original.

Bien es cierto que podría hablarse de nuevas concepciones fantásticas asentadas sobre las bases expansivas del videojuego. Las distintas posibilidades que presenta el medio, quebrando las necesidades de categorización y sirviéndose de una retroalimentación entre elementos propios y adquiridos culturalmente, hacen que la consideración fantástica alcanza nuevas cotas, no sólo a nivel formal sino incluso exclusivo. De esta forma, se acude a una referencialidad que deja muy a las claras la acción que el mundo cotidiano y su desarrollo cultural acaban provocando en la esfera jugable. Del mismo modo, la naturaleza interactiva del medio provoca que la experiencia final posea consideraciones desde diversos ámbitos y puntos de vista. Por tanto, el conocimiento previo por parte del jugador, tanto del universo planteado (y sus referencias) como de las convenciones y/o elementos presentados por el videojuego como medio, provocan que la experiencia resultante presente distintos resultados, todos de una importancia considerable en lo que, a la concreción fantástica, general y particular del medio, se refiere.

Volviendo al asunto del jugador, la doble perspectiva creadora y elaboradora del videojuego presenta una nueva problemática para el aislamiento completo. Por 
un lado, ciñéndonos a una obra en cuestión, es posible establecer una serie de parámetros preestablecidos en su creación que la hacen acreedora de la apreciación como fenómeno propio y, por tanto, con necesidad de inmersión por parte del jugador. Sin embargo, es precisamente esta figura la que acaba haciendo la experiencia propia, tanto en su aplicación como en su resultado. Existe una elaboración autoral por parte del jugador, en tanto participante de una experiencia conocida y aceptada, pero también desempeñada y concluida por una figura externa a la obra.

\section{Referencias bibliográficas}

Bateson, G. (1954). Steps to an Ecology of Mind (Univ of Chicago PR ed.). Chicago: University of Chicago Press.

Bettelheim, B. (1976). Psicoanálisis de los cuentos de hadas (1. a ed.). Barcelona: Crítica.

Bowman, S.L (2010). The Functions of Role-playing Games: How Participants Create Community, Solve Problems and Explore Identity. Jefferson: McFarland.

Campos Méndez, A.F. (2019). Análisis sobre la relevancia narrativa de los espacios en la saga Soulsborne. (Trabajo Fin de Máster Inédito). Universidad de Sevilla, Sevilla. Recuperado de https://hdl.handle.net/11441/89299

Collantes, X. R. (2013). Juegos y videojuegos. Formas de vivencias narrativas. En C. A. Scolari (ed.), Homo videoludens: de Pacman a la gamification (pp. 20-51). Barcelona: Collecció Transmedia XXI.

Donaldson, S. R. (1986). Epic Fantasy in the Modern World. Kent: Kent State University Libraries.

Dolezel, L. (1999). Heterocosmica. Ficcion y Mundos Posibles. Madrid: ARCO/LIBROS.

Egenfeldt-Nielsen, S., Smith, J. H., \& Tosca, S. P. (2015). Understanding Video Games: The Essential Introduction (3rd ed.). Londres: Routledge.

Huizinga, J. (1972). Homo ludens (1. ${ }^{a}$ ed.). Madrid: Alianza.

Juul, J. (ed.). (2008). The Magic Circle and the Puzzle Piece. Recuperado de: https://publishup. uni-potsdam.de/opus4-ubp/frontdoor/index/index/docId/2554

Mendizábal, I. R. (2004). Máquinas de pensar. Videojuegos, representaciones y simulaciones de poder. Quito: Abya Yala.

Muñoz Rengel, J. J. (2010). La narrativa fantástica en el siglo xxi. Ínsula, 765, 6-10. Recuperado de https://juanjacintomunozrengel.com/Descargas/La\%20narrativa\%20fantastica\%20en\%20el\%20siglo\%20XXI\%20-\%20JJ\%20Munoz\%20Rengel.pdf

Nikolajeva, M. (2003). Fairy Tales and Fantasy: From Archaic to Postmodern. Marvels \& Tales, 17 (1), 138-156. Recuperado de https://digitalcommons.wayne.edu/marvels/ vol17/iss $1 / 8$

Pérez Latorre, O. (2011). Géneros de juegos y videojuegos. Una aproximación desde diversas perspectivas teóricas. Comunicació: Revista de Recerca i d'Anàlisi [Societat Catalana de Comunicació], 28(1), 127-146. https://doi.org/10.2436/20.3008.01.81 
Rick, D.W. (2019). Rhetorics of the Fantastic: Re-Examining Fantasy as Action, Object, and Experience [Tesis doctoral]. University of Arizona, Arizona. Recuperado de http://hdl. handle.net/10150/631281

Roas, D. (2009). Lo fantástico como desestabilización de lo real: elementos para una definición. En T. López Pellisa y F. A. Moreno (Eds.), Ensayos sobre ciencia ficción y literatura fantástica: actas del Primer Congreso Internacional de literatura fantástica y ciencia ficción, vol. 8, (pp. 94-120). Madrid: Asociación Cultural Xatafi \& Universidad Carlos III de Madrid.

Tzvetan, T. (1982). Introducción a la literatura fantástica. Mexico: Ediciones Coyoacán.

Venegas Ramos, A. (22 de Mayo de 2018). Retrolugares, escenarios imaginados del pasado en la cultura popular y el videojuego. Presura. Recuperado de http://www.presura.es/ blog/2018/05/22/retrolugares-videojuegos/ 